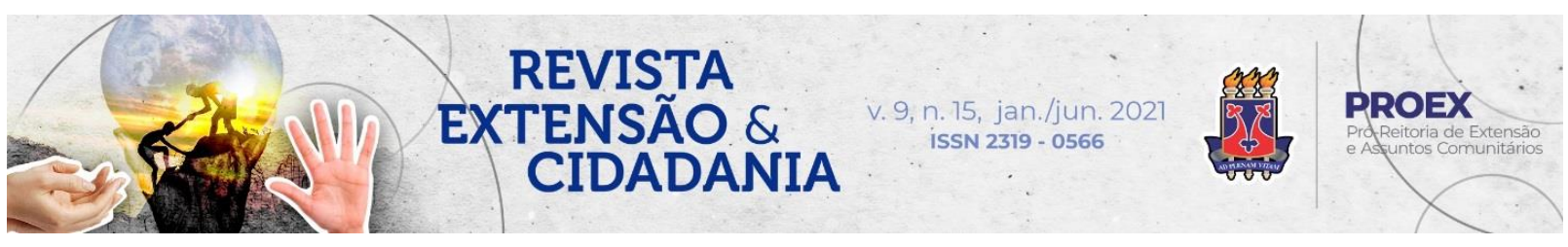

DOI: $10.22481 /$ recuesb.v9i15.8649

\title{
SISTEMAS AVALIATIVOS E O ENSINO REMOTO EMERGENCIAL
}

\author{
Evaluation systems and remote emergency education
}

Maria Clara Rabelo Jaime $^{1}$
Ellen Eloise de Oliveira $^{2}$
Soraya Corrêa Domingues $^{3}$

Resumo A partir da declaração da OMS sobre a Pandemia do Coronavírus, diferentes estratégias buscaram minimizar o contágio do vírus com medidas profiláticas, como o distanciamento social. Neste contexto, a escola precisou adaptar o processo de ensino presencial para remoto emergencial, alterando os sistemas metodológicos e avaliativos para atender as atuais demandas. Com isso, o presente artigo buscou analisar os sistemas avaliativos adotados por nove instituições de ensino básico da cidade de Curitiba-PR e região metropolitana, entre privadas e públicas, objetivando apresentar seus respectivos métodos e compreender estratégias adotadas. Como caminho metodológico, optou-se pela análise qualitativa expositiva, através de entrevista semiestruturada realizada de forma remota com docentes. Por fim, pode-se considerar que existem diferentes sistemas avaliativos que estão em consonância com o método usado pela escola no processo ensino-aprendizagem remoto e particularidades diversas são evidentes, relacionadas à inserção tecnológica no ambiente escolar, a não aferição da aprendizagem por verificação e exames, e entre os sistemas escolares e a ampliação ou limitação desses métodos. Conclui-se que as inovações do sistema avaliativo são alicerce para argumentações e melhorias no sistema tradicional, sua exposição evidencia a necessidade de possibilidades que auxilia as adaptações pedagógicas no contexto atual da forma mais equilibrada possível.

Palavras-chave: Avaliação escolar. Educação. Pandemia. Ensino Remoto Emergencial. Curitiba.

Abstract: Based on the WHO declaration on the Coronavirus pandemic, different strategies sought to minimize the contagion of the virus with prophylactic measures, such as social detachment. In this context, the school needed to adapt the face-to-face teaching process to the remote emergency, changing the methodological and evaluative systems to meet the current

\footnotetext{
${ }^{1}$ Graduanda em Educação Física, pela Universidade Federal do Paraná, Curitiba, Paraná, Brasil. Orcid: https://orcid.org/0000-0002-7525-4908 E-mail: mariarabelo@ufpr.br

${ }^{2}$ Graduanda em Educação Física, pela Universidade Federal do Paraná; graduanda em Pedagogia, pela Pontifícia Universidade Católica do Paraná, Curitiba, Paraná, Brasil. Orcid: https://orcid.org/0000-0003-2569-5139 E-mail: ellenoliveira@ufpr.br

${ }^{3}$ Professora da Universidade Federal do Paraná, Coordenadora do projeto de extensão Pesquisa e Licenciar sobre Ensino híbrido em período de pandemia na Dimensão da Educação Ambiental. Orcid: https://orcid.org/0000-0001-7486-8425 E-mail: correadomingues@ufpr.br
} 
demands. With this, the following article sought to analyze the evaluation models adopted by nine basic education institutions in the city of Curitiba-PR and the metropolitan region, between private and public ones, aiming to present their respective methods and understand adopted strategies. As a methodological approach, a qualitative expository analysis was carried out, through a semi-structured interview carried out remotely with physical education teachers. Finally, it can be considered that there are different evaluation models that are in line with the method used by the school in the remote teaching-learning process and several particularities are evident, related to the technological insertion in the school environment, the non-measurement of learning by verification and exams, and between school systems and the expansion or limitation of these methods. It is concluded that, that the innovations of the evaluation system are the foundation for arguments and improvements in the traditional system, its exposition evidences the need for possibilities that helps the crossing of this moment in the most balanced way possible.

Keywords: School evaluation. Education. Pandemic. Emergency Remote Teaching. Curitiba.

\section{Introdução}

Em fevereiro de 2020, o Brasil registrou o primeiro caso de Covid-19, contaminação pelo Coronavírus Sars-cov-2, que possui como principal vetor de transmissão gotículas de saliva emitidas por pessoas infectadas. Os sintomas incluem, febre alta, dor de garganta, tosse seca, dores de cabeça, perda de olfato e paladar, entre outros. Sabe-se que a vacina e as medidas de segurança recomendadas pelo Ministério da Saúde (BRASIL, 2020), que incluem o uso de máscaras, higienização frequente das mãos e distanciamento social, são as únicas maneiras para diminuir os índices de contaminação e proliferação do Coronavírus.

Diante de um cenário de rápida proliferação do vírus e do reconhecimento da Pandemia pela Organização Mundial da Saúde (OMS, 2020), foi necessário readaptar inúmeros hábitos e costumes de convívio social, havendo a necessidade de suspensão de atividades presenciais que gerassem aglomeração como medida preventiva. Neste contexto, instituições de ensino básico e superior tiveram suas atividades presenciais suspensas, segundo a Organização das Nações Unidas para a Educação (UNESCO, 2020), a paralisação de atividades presenciais nessas instituições impactou 191 países, um total de 1,57 bilhões de estudantes.

Ainda em março de 2020, o Brasil adotou medidas para assegurar a continuidade do ensino com a autorização do Ministério da Educação (BRASIL, 2020), através da publicação da Portaria $n^{\circ} 343$, de 17 de março de 2020, Art. $1^{\text {o }}$ que estabelece: “autorizar, em caráter excepcional, a substituição das disciplinas presenciais, em andamento, por aulas que utilizem

Revista Extensão \& Cidadania, v. 9, n. 15, p. 93-109, jan./jun. 2021.

ISSN 2319-0566 DOI: 10.22481/recuesb.v9i15.8649 
meios e tecnologias de informação e comunicação, nos limites estabelecidos pela legislação em vigor" (BRASIL, 2020). Houve, então, a necessidade de remodelar a estrutura educacional para suprir as limitações causadas pela Pandemia, migrando o Ensino Presencial para a modalidade de Ensino Remoto Emergencial.

O Ensino Remoto Emergencial (ERE), embora tenha suporte de recursos tecnológicos para desenvolver atividades pedagógicas, difere das modalidades de Ensino à Distância (EaD) tendo em vista que este se configura como uma modalidade Emergencial. O Ensino Remoto permite o desenvolvimento de componentes curriculares obrigatórios que deveriam ser construídos em sala de aula, de maneira síncrona, sem muitos prejuízos, através do uso de recursos, como Google Meet, Zoom, Microsoft Teams, com atuação e suporte docente durante o momento da aula, permitindo, por meio dos "encontros online", que a relação pedagógica não desapareça totalmente.

A Educação a Distância, modelo que já se fazia presente no Brasil, antes mesmo da Pandemia da Covid-19, difere-se do modelo Emergencial, uma vez que ocorre uma preparação estruturada, fator não encontrado na mudança repentina para o Ensino Remoto Emergencial (BRITO; COSTA, 2020). Segundo Hodges, Moore, Trust, Bond (2020), as modalidades à distância e remota se diferenciam, pois, a Educação a Distância conta com recursos e uma equipe multiprofissional preparada para ofertar os conteúdos e atividades pedagógicas; diferentes mídias em plataformas online; uma carga horária híbrida, a qual pode ser cumprida de acordo com a preferência e disponibilidade do estudante; tutores, que podem auxiliar a todo instante; contextualização dos conteúdos através de recursos digitais e midiáticos; plataformas específicas para suportar os conteúdos; e as atividades são, na grande maioria das vezes, ofertadas de forma assíncrona, bem como os "encontros" online.

As alterações necessárias na passagem para o Ensino Remoto Emergencial também impactaram as metodologias de ensino, currículos e sistemas avaliativos, que foram reformulados para atender às necessidades do atual contexto. Verificando tais alterações, a partir de desdobramento de estudos, observações de campo, entrevistas e círculos de conversas com a comunidade escolar relacionada às Atividades do Projeto de Extensão e do Programa Licenciar em Tempos de Pandemia e Isolamento Social, durante o ano de 2020, na Universidade Federal do Paraná, o presente artigo possui como objetivo apresentar resultados obtidos através de entrevistas realizadas com escolas do município de Curitiba. Para tanto, foi adotado o método

Revista Extensão \& Cidadania, v. 9, n. 15, p. 93-109, jan./jun. 2021.

ISSN 2319-0566 DOI: 10.22481/recuesb.v9i15.8649 
de pesquisa qualitativo social (CRESWELL, 2010), o qual permite analisar mudanças proporcionadas pela modalidade de Ensino Remoto Emergencial no contexto avaliativo.

\section{Metodologia}

O presente estudo foi desenvolvido com base no método de pesquisa qualitativa, realizada por meio de entrevistas em videoconferência e $e$-mail com docentes de diferentes escolas. Foram escolhidas as respostas de nove escolas pela complexidade das respostas, do total de quarenta, sendo três municipais, duas estaduais e quatro particulares, do município de Curitiba. Com as respostas dessas entrevistas, foi possível levantar dados acerca da estrutura escolar e pedagógica em tempos de Pandemia.

Docentes que participaram desta pesquisa fazem parte de um grupo parceiro entre escolas da Rede Básica de Ensino, Projeto de Extensão e Programa Licenciar em torno da temática Educação Remota em Tempos de Pandemia. Essas atividades extensionistas envolvem crianças, pais e responsáveis e comunidade escolar que, durante o período de isolamento social, foram redimensionadas para atender as atuais demandas da comunidade, dentre elas, compreender a vida dos participantes em isolamento social, em relação ao seu tempo de lazer, às práticas corporais e ao ensino e aprendizagem com a escola. Integrado a essas atividades extensionistas, o grupo do Programa Licenciar elaborou roteiro de observação de campo produzindo relatórios científicos, rodas de conversa e entrevistas para compreender os métodos híbridos e remotos em tempos de Pandemia. O roteiro da entrevista contou com dez perguntas, envolvendo temas como acessibilidade, metodologia de ensino e avaliação, todas relacionadas ao Ensino Remoto Emergencial realizado durante o ano de 2020.

Após a coleta de dados, foi feita uma análise para identificar elementos essenciais das pesquisas, entre eles destacou-se a seguinte problemática: "Como as escolas estão desenvolvendo seus sistemas avaliativos?’(DOMINGUES; JAIME, 2020, p. 9) A partir disso, foram selecionadas duas perguntas do roteiro que possuíssem relação com a temática para serem utilizadas como instrumento de análise qualitativa (CRESWELL, 2010), a saber: "Estratégias Metodológicas no período da Pandemia", "Qual o método utilizado pela escola para manter o processo ensino aprendizagem com seus estudantes? Por sites? Por aulas gravadas? Por lives? Que tipo de aplicativo ou plataforma está sendo usado? Se possui grupo

Revista Extensão \& Cidadania, v. 9, n. 15, p. 93-109, jan./jun. 2021.

ISSN 2319-0566 DOI: 10.22481/recuesb.v9i15.8649 
de pais por redes sociais? Etc." e "Como está sendo organizado o processo avaliativo dos estudantes?" (DOMINGUES; JAIME, 2020, p. 9).

\section{Processo de Ensino-Aprendizagem no ERE}

Ensinar é uma aventura criadora, segundo Freire (1968), e mais do que nunca, no contexto atual, é preciso ter criatividade para reinventar os saberes e métodos todos os dias. Em março de 2020, instituições de ensino de todo o Brasil, que até então seguiam um modelo mais tradicional e encontravam dificuldades para inserir recursos digitais e tecnológicos em processos de ensino-aprendizagem (BITTENCOURT; ALBINO, 2017) seja por falta de recursos, ou ausência de formação continuada, se viram obrigadas a romper com alguns destes dilemas, para que as atividades pedagógicas continuassem na categoria de Ensino Remoto Emergencial.

A análise do atual Ensino Remoto Emergencial foi realizada a partir de observações de campo, entrevistas e círculos de conversa elaborados pelo grupo do Projeto de Extensão e o do Programa Licenciar. Neste estudo, primeiramente destacou-se respostas dadas as entrevistas de quarenta escolas da Rede Básica de Ensino de Curitiba abordando assuntos sobre métodos, conteúdos, currículos, e sistemas avaliativos, e posteriormente, para as compreender os sistemas avaliativos, destacou-se nove respostas de diferentes escolas baseado na complexidade de suas informações. As escolas são três municipais (M), duas estaduais (E) e quatro particulares (P), que serão caracterizadas respectivamente pelas siglas M1, M2 e M3, E1 e E2, e P1, P2, P3 e P4, com a numeração referente a posição na ordenação alfabética. O intuito da pergunta estava no levantamento dos recursos adotados pelas instituições para manter o processo de ensino aprendizagem, embora, algumas apresentassem distinções, foi possível perceber semelhança na estruturação das propostas e atividades.

As escolas M1, M2 e M3, por se configurarem como escolas da Rede Municipal de Ensino de Curitiba, apresentam suas propostas veiculadas pela Tv Escola Curitiba, que possui um canal do YouTube e um canal televisivo, o qual diariamente, são transmitidos vídeos com propostas pedagógicas ministradas por docentes específicos para cada nível de ensino e/ou componente curricular, os quais fazem parte tanto do Núcleo de Educação Municipal de Curitiba, quanto de Regionais de Ensino dos bairros da capital. M1, M2 e M3, também fazem o uso de outros aplicativos, como Google Classroom, WhatsApp e Grupos de Facebook, para

Revista Extensão \& Cidadania, v. 9, n. 15, p. 93-109, jan./jun. 2021.

ISSN 2319-0566 DOI: 10.22481/recuesb.v9i15.8649 
complementar tarefas e manter contato com responsáveis e estudantes. Ocorre, quinzenalmente, a entrega de atividades impressas, as quais, possuem como objetivo complementar saberes transmitidos através dos vídeos com propostas. Tendo em vista a situação vulnerável que alguns estudantes se encontram, por exemplo, M2 oferece empréstimos de materiais didáticos da escola. As escolas E1 e E2, estaduais, possuem a mesma configuração das municipais, nas quais as aulas são transmitidas por um canal de televisão, Tv Paraná, e também contam com o aplicativo Aula Paraná, o qual pode ser baixado em lojas de sistemas operacionais (Android e $I O s)$. E1 buscou ofertar livros tanto em formato físico, quanto digital, criou grupos de WhatsApp para facilitar a comunicação entre docentes e estudantes, oferecendo atividades impressas. Já E2, optou por deixar todas as atividades em formato online, pelo aplicativo Google Classroom.

Escolas P1, P2, P3 e P4, particulares, possuem algumas distinções entre si, principalmente no que se diz respeito às metodologias e escolhas de sites e plataformas. P1, inicialmente, adotou apenas o Moodle como uma opção para acompanhar a aprendizagem dos estudantes, cada nível de ensino com competências específicas e condizentes com documentos oficiais, Decreto n. ${ }^{\circ}$ 01/2020 do Conselho Estadual de Educação (PARANÁ, 2020) passou a utilizar a Plataforma Microsoft Teams. Plataforma que possibilita interações síncronas e assíncronas voltadas para organizar conteúdo e tempo pedagógico necessários em cada uma das etapas de ensino. As atividades didáticas são enviadas via Moodle com acompanhamento docente e estagiários e estagiárias, auxiliando famílias e estudantes quanto às dificuldades de acesso e à informação acerca de materiais utilizados. Os comunicados são feitos pelas redes sociais da instituição.

P2 também faz o uso da Plataforma Microsoft Teams e permite a interação dos estudantes a todo momento, já que as aulas são ao vivo, arquivos com tarefas são compartilhados pela própria plataforma, a coordenação realiza contato com familiares via $e$ mail e telefone, e postam atividades lúdicas que não possuem caráter obrigatório e podem ser realizadas a qualquer momento. P3, faz uso da mesma plataforma que P1 e P2, porém, as videoaulas são postadas e estudante devem assistir de acordo com uma determinada ordem, é realizado um encontro síncrono por semana com as turmas. Os pais se utilizam de uma ferramenta própria da instituição para manter contato, e a escola faz uso de $e$-mail e telefone para manter contato.

P4, se utiliza da plataforma Zoom, onde ocorrem encontros e atividades conforme o horário normal das aulas, as atividades são enviadas via $e$-class, no qual estão prazos, vídeos e

Revista Extensão \& Cidadania, v. 9, n. 15, p. 93-109, jan./jun. 2021.

ISSN 2319-0566 DOI: 10.22481/recuesb.v9i15.8649 
áudios com explicações, a equipe pedagógica busca dar o suporte às famílias, por e-mail e redes sociais, cada turma possui um grupo de WhatsApp com docente, para que seja possível esclarecer dúvidas e manter o contato.

O levantamento realizado com as escolas públicas e particulares é possível perceber a remodelação educacional até então vigente, nesta remodelação, algumas instituições adotam artifícios para manter o contato mais próximo na relação entre docentes e estudantes, já em outras, ocorre um distanciamento. Além disso, nota-se a inserção de recursos e aplicativos como ferramentas pertinentes para o trabalho docente, os quais permitem novas possibilidades e descobertas, tanto para estudantes quanto para os docentes:

A utilização cada vez maior, das mídias digitais no ambiente acadêmico e corporativo como estratégia, com um público cada vez mais envolvido com a tecnologia, trazem para as instituições várias opções de recursos didáticos para lhes dar a oportunidade de responder às diferenças individuais e às múltiplas facetas da aprendizagem. (BITTENCOURT; ALBINO, 2017, p. 209)

É necessário, contudo, se apropriar do uso de tecnologias, “essas novas aprendizagens, quando colocadas em práticas, reorientam todos os nossos processos de descobertas, relações, valores e comportamentos" (KENSKI, 2012, p. 44). Desse modo, mostram tanto para docentes, quanto para estudantes que a tecnologia pode se fazer presente como uma aliada não só ao processo de ensino-aprendizagem, mas em inúmeros processos presentes em seu cotidiano.

\section{Avaliação da aprendizagem}

A avaliação é uma preocupação do processo de ensino-aprendizagem com grande relevância nas ações educativas, ela é importante para o conhecimento de si mesmo, do outro e do ambiente pedagógico. Deve estar baseada no acolhimento do docente com os seus estudantes, opondo-se ao simples julgamento e respeitando as singularidades de cada um (LUCKESI, 2000).

Essas avaliações não são neutras, mas inseridas em um contexto educacional e subordinadas ao processo pedagógico adotado, tendo relação direta da sua funcionalidade com o sentido e o significado trazidos pelo docente (CHUEIRI, 2008). Assim, elas devem passar por dois processos, o de diagnosticar, composto pela coleta de dados, a especificação do conteúdo e a determinação dos instrumentos que serão usados para, posteriormente, promover

Revista Extensão \& Cidadania, v. 9, n. 15, p. 93-109, jan./jun. 2021.

ISSN 2319-0566 DOI: 10.22481/recuesb.v9i15.8649 
a qualificação, a transformação dos resultados em uma medida padrão previamente estabelecida, como o sistema de notas. A avaliação é, então, um sistema estrutural finalizado com a tomada de decisão que visa ao alcance de melhorias no desenvolvimento e na aprendizagem (LUCKESI, 2000).

Para que a avalição aconteça, deve ter um objetivo específico, que podem variar em, segundo Luckesi (1998): a) apenas registrar; b) oferecer uma oportunidade de melhoria da nota; ou c) atentar-se para as dificuldades e facilidades criando um caminho para o desenvolvimento da educação. Porém, "a sala de aula é o lugar onde, em termos de avaliação, deveria predominar o diagnóstico como recurso de acompanhamento e reorientação da aprendizagem" (LUCKESI, 2005, p. 47), ou seja, apenas o último tópico teria um objetivo avaliador, sendo importante não confundir a avaliação com o sistema de exames ou de verificação, já que além de necessitar da tomada de decisão "é amorosa, inclusiva, dinâmica e construtiva, diversa dos exames, que não são amorosos, são excludentes, não são construtivos, mas classificatórios. A avaliação inclui, traz para dentro; os exames selecionam, excluem, marginalizam" (LUCKESI, 2000, p. 1).

A necessidade de uma atitude acolhedora evidencia que as relações sociais no ambiente da sala de aula são essenciais para o desenvolvimento dos conteúdos programados, a relação estudante-estudante e estudante-docente deve ser considerada, visto que a aprendizagem não é apenas um processo cognitivo, mas também social (HODGES; MOORE; LOCKE; TRUST; BOND, 2020). A relação docente-estudante, principalmente, auxilia na percepção de dificuldades durante o cotidiano presencial, permitindo uma maior individualidade na orientação e adaptação das propostas (OLIVEIRA; SOUZA, 2020), devendo ser modificada a partir da realidade e necessidade dos estudantes, já que a educação precisaria ser firmada em um processo comunicativo (KUNZ, 1991), ajudando na construção de uma avaliação processual, que mostre caminhos para um maior alcance no desenvolvimento educacional (DOMINGUES, 2020).

Nesse sentido, com a intenção de seguir as atividades educacionais de forma remota emergencial, as tendências nas estratégias pedagógicas foram adaptadas em sintonia com a metodologia adotada pela escola para manter o processo de ensino-aprendizagem, gerando interferência direta nos sistemas avaliativos. Nos métodos tradicionais, eles costumam ser realizados de forma pontual, fragmentada e disciplinar com documentos, principalmente no formato de provas teóricas, buscando uma classificação dos estudantes, gerando sentimentos negativos como medo e ansiedade (NASCIMENTO; GIMENIZ-PASCHOAL, 2008).

Revista Extensão \& Cidadania, v. 9, n. 15, p. 93-109, jan./jun. 2021.

ISSN 2319-0566 DOI: 10.22481/recuesb.v9i15.8649 
Assim, "existem situações conflitantes, desafiantes, que a aplicação de técnicas convencionais, simplesmente não resolve problemas" (SCHON, 1997, p. 21), sendo que os métodos avaliativos tradicionais pautados evolutivamente em examinar, medir, classificar e qualificar (CHUEIRI, 2008), tiveram que ser adaptados para melhor avaliar os estudantes durante o Ensino Remoto Emergencial.

Então, após a realização de entrevista com equipe pedagógica de escolas da Rede Básica de Curitiba e região metropolitana, a pergunta: "Como está sendo organizado o processo avaliativo dos estudantes?" (DOMINGUES; JAIME, 2020, p. 20), foi analisada, segundo método qualitativo de Creswell (2010), relacionando as atividades avaliativas dos processos pedagógicos de diferentes unidades escolares. Ao todo, o sistema avaliativo de nove escolas foi aqui destacado e estão classificadas em M1, M2, M3, E1, E2, P1, P2, P3 e P4 como já explicitado anteriormente.

De início, vemos uma grande quantidade de escolas, principalmente as públicas, utilizando atividades impressas como forma de avaliação dos estudantes, a escola E1 adotou o modelo para os casos nos quais o estudante não tem recurso nas atividades online: "[...] Há também as avaliações impressas disponíveis para estudantes que não têm acesso à plataforma do ClassRoom" (DOMINGUES; JAIME, 2020, p. 19).

Algumas adotaram as atividades impressas como avaliação para todos os estudantes, de forma integral, como a escola M1 afirma, "Todos os processos avaliativos derivam da entrega de atividades impressas retiradas na secretaria da escola, os estudantes não fazem nenhum processo avaliativo online devido a idade das crianças" (DOMINGUES; JAIME, 2020, p. 9), enquanto outras as associaram, como a escola M3 "[...] pensam em formas avaliativas voltadas aos registros no caderno, das atividades propostas pelas videoaulas, e o retorno das atividades quinzenais propostas pela escola” (DOMINGUES; JAIME, 2020, p. 68).

Nesse sentido, algumas escolas buscam nos registros do caderno essa avaliação, o que também está mais restrito às escolas públicas, como ressaltado pela escola M3 citada anteriormente, além da escola M4, a qual afirma que "após o período de Pandemia, as anotações feitas nos cadernos contarão como notas" (DOMINGUES; JAIME, 2020, p. 77), considerandose como um método físico de controle da participação das videoaulas veiculadas pela prefeitura de Curitiba.

Enquanto as escolas municipais apresentaram uma preocupação na validação da participação nas aulas pelos registros no caderno, outras escolas também registram a frequência

Revista Extensão \& Cidadania, v. 9, n. 15, p. 93-109, jan./jun. 2021.

ISSN 2319-0566 DOI: 10.22481/recuesb.v9i15.8649 
ativa nas aulas como forma avaliativa, isso é visível nas escolas privadas que adotaram majoritariamente modelos de aulas síncronas por diferentes plataformas. As escolas P2 e P4 trazem isso mais nitidamente, sendo que, respectivamente "Estudantes são avaliados pela presença nas aulas e atividades concluídas na plataforma" (DOMINGUES; JAIME, 2020, p. 31) e o "Processo avaliativo se dá pela conclusão das atividades [...] presença, participação e interação nas aulas" (DOMINGUES; JAIME, 2020, p. 40).

As atividades processuais em plataformas que podem ser feitas ao decorrer da semana foram realizadas pelos estudantes, supervisionadas e avaliadas pelos docentes mais rapidamente frente aos materiais impressos e possibilidades de recursos digitais, na escola E1 “[...] há pequenas avaliações após o término de cada aula ministrada pela TV Paraná além das atividades que os docentes podem postar na plataforma [...]"(DOMINGUES; JAIME, 2020, p. 19).

E2 “[...] são feitas através do ClassRoom onde os docentes podem avaliar os quizzes [...]" (DOMINGUES; JAIME, 2020, p. 28); P1 onde “[...]é feita a partir da entrega das tarefas solicitadas nas aulas, como pesquisas, vídeos ou fotos realizando a atividade, que são postadas na Plataforma Moodle [...]" (DOMINGUES; JAIME, 2020, p. 24) e a escola P4 que o processo avaliativo se pauta nessas atividades em plataforma própria. Além disso, em algumas escolas acontecem avaliações pontuais disciplinares, através de questionários, como a escola P3 “Todas as avaliações estão sendo teóricas e realizadas através do Microsoft Forms" (DOMINGUES; JAIME, 2020, p. 37) e P1:

[...] também são realizadas atividades avaliativas em formato de questionário ("provas") online, geralmente de duas disciplinas por semana, onde são disponibilizadas questões sobre os temas discutidos durante o trimestre (com perguntas descritivas, qualitativas, de completar frase, etc) e os estudantes possuem um tempo máximo (normalmente 72 horas) e 2 ou 3 tentativas para finalizar o questionário dependendo da disciplina. (DOMINGUES; JAIME, 2020, p. 24)

Assim, é possível perceber certa autonomia docente nas decisões avaliativas, nas escolas municipais, fica restrita à produção das atividades impressas, nas estaduais, docentes podem complementar o material que recebem e são produzidos pela da secretaria da educação, ou seja, essas são usadas e integradas, conforma resposta da escola E1, pelas “....atividades que docentes podem postar na plataforma” (DOMINGUES; JAIME, 2020, p. 19), além de que “[...] o docente pode mandar uma nova prova no classroom." (DOMINGUES; JAIME, 2020, p. 27), depoimento da E2.

Revista Extensão \& Cidadania, v. 9, n. 15, p. 93-109, jan./jun. 2021.

ISSN 2319-0566 DOI: 10.22481/recuesb.v9i15.8649 
Nas escolas particulares o docente fica responsável pela quantidade de atividades, conforme citado pela escola P1 " [...] cada estudante tem acesso a uma sala virtual da turma que pertence, com as disciplinas organizadas separadamente. [...]" (DOMINGUES; JAIME, 2020, p. 24). O modelo adotado por esta instituição permite que docentes estejam em contato direto com estudante, direcionando as atividades avaliativas.

Por fim, o uso associado de diferentes formas de avaliação também mostrou uma estratégia pedagógica viável, permitindo múltiplos métodos de acompanhamento, processuais ou pontuais, análise de frequência e possibilitando contemplar estudantes que apresentaram dificuldades momentâneas de recursos tecnológicos e acesso conforme a resposta da escola P1:

Uma parte da avaliação é feita a partir da entrega das tarefas solicitadas nas aulas (pesquisas, vídeos ou fotos realizando as atividades), que são postas na Plataforma Moodle, onde cada estudante tem acesso a uma sala virtual da turma que pertence, com as disciplinas organizadas separadamente. Além disso, também são realizadas atividades avaliativas em formato de questionário ("provas") online, geralmente de duas disciplinas por semana, onde são disponibilizadas questões sobre os temas discutidos durante o trimestre (com perguntas descritivas, qualitativas, de completar a frase, etc) e os estudantes possuem um tempo máximo (normalmente 72 horas) e 2 ou 3 tentativas para finalizar o questionário dependendo da disciplina. Esse questionário, também é realizado na Plataforma Moodle. Para os estudantes que não tiveram acesso a Plataforma Moodle nos dias que a atividade avaliativa estava disponível, é realizada a segunda chamada (DOMINGUES; JAIME, 2020, p. 25).

\section{Discussão}

A partir das análises, percebe-se que as escolas buscam encontrar sistemas avaliativos para suprir a necessidade de adaptação dos modelos de ensino durante o período de adesão ao ensino remoto emergencial. Dentro de suas particularidades e de formas condizentes às suas metodologias, aderir sistemas avaliativos, conforme as possibilidades escolares, evidenciam o contraste de recursos e ferramentas entre o público e o privado, pois na maioria dos tópicos, citados anteriormente, a divergência de métodos, materiais, instrumentos, a flexibilização de formas usadas no ensino privado e o limite avaliativo do público, principalmente das escolas municipais, se faz presente. Segundo Rondini, Pedro e Duarte (2020), após pesquisa qualitativa, as escolas públicas apresentaram maiores dificuldades em relação aos recursos e possibilidades, o que dificulta o ensino amplo e democrático, enquanto para as escolas particulares, o processo

Revista Extensão \& Cidadania, v. 9, n. 15, p. 93-109, jan./jun. 2021.

ISSN 2319-0566 DOI: 10.22481/recuesb.v9i15.8649 
de adaptação ao ensino remoto emergencial foi mais rápido, e está abrindo possibilidades para o uso de tecnologias nas aulas.

A utilização de meios de informação e de comunicação foi necessária para a continuação do processo educativo, sendo por canais de comunicação, plataformas online, entre outros mecanismos, porém alguns métodos foram mantidos no instrumento tradicional escolar do uso do papel, principalmente nas escolas públicas municipais. Majoritariamente, isso é utilizado para evitar casos de exclusão por dificuldades de acesso ou de recursos, cumprindo o seu papel de ser um direito de todos, evitando a exclusão social e o distanciamento completo do ambiente escolar, conforme artigo n. 205 do texto da Constituição Nacional: "A educação, direito de todos e dever do Estado e da família" (BRASIL, 1988). Contudo, a escola M1 trouxe a argumentação da idade dos estudantes para realização das atividades avaliativas online. Todavia para Palfrey e Gasser (2011), esses estudantes são nativos digitais, já que ao nascerem, após a reconstrução social de 1980, tem determinada quantidade de acesso e habilidade para uso dessas tecnologias.

Não cabe aqui se posicionar acerca da falta de recursos tecnológicos das famílias brasileiras, mas apresentar limitações para realização dessas atividades avaliativas, com essa argumentação também é possível relacionar a dificuldade de conhecimento docente acerca dos meios digitais para educação, pois é perceptível a incorporação de novos métodos de ensino como uma dificuldade enfrentada. Isso se evidencia pela falta de estrutura na escola e na educação remota realizada em casa, e também pela formação docente deficitária para trabalhar com essas ferramentas (RONDINI; PEDRO; DUARTE, 2020). Segundo Bittencourt e Albino (2017), os docentes, em sua maioria, são imigrantes digitais e deveriam ter uma formação continuada, além de suporte para compreender as tecnologias existentes, visto que com a adaptação repentina para o formato online, isso não foi possível (BRITO; COSTA, 2020).

Todas as escolas apresentam mecanismos semelhantes de aferição de conhecimentos, que estão de acordo com as exigências do sistema escolar tradicional presencial. Sendo perceptível que as ferramentas tecnológicas disponíveis não são exploradas na sua totalidade, segundo já relatado por Brito e Costa (2020), as escolas utilizam as inovações de forma parcial. As que mostraram maior diversidade avaliativa, evidenciam uma busca por modelos pluralizados, que tenham uma base mais estruturada na coleta de aprendizados interiorizados. Ou seja, existem diversas linguagens que envolvem os estudantes no seu desenvolvimento de forma individual e múltipla.

Revista Extensão \& Cidadania, v. 9, n. 15, p. 93-109, jan./jun. 2021.

ISSN 2319-0566 DOI: 10.22481/recuesb.v9i15.8649 
Esses aprendizados são ensinados e se expressam de formas diferentes dependendo das suas particularidades (GONÇALVES; ANTONIO, 2007). É um processo de forma acentuada que beneficia características particulares e individuais, pois seus conhecimentos se expressam por diversas linguagens e devem ser observados e acolhidos como tal dentro de um sistema avaliativo complexo. Porém, ainda é visível a superioridade na aferição com tendências da linguagem de expressão escrita, ou seja, a diversificação na aprendizagem abre espaço para que novas formas de avaliação se façam presentes e para que o estudante seja avaliado por completo, em uma educação voltada ao seu desenvolvimento integral (BRASIL, 2018). Mesmo sendo ainda está limitada, assim como na avaliação realizada presencialmente em sistemas avaliativos voltados a oralidade e escrita (GONÇALVES; ANTONIO, 2007).

O planejamento avaliativo exposto por Luckesi (2000) sobre a especificidade de conteúdos para a avaliação, a autonomia docente nas decisões é importante para que este tome como recorte avaliativo um tema curricular específico que tenha necessidade do diagnóstico para embasamento sobre a continuação da aprendizagem significativa, tema que será percebido pelo contato do docente com a turma nas relações presentes nos ambientes pedagógicos. Entre as escolas pesquisadas percebeu-se a busca por uma adaptação da avaliação para o sistema processual, em contraposição ao pontual, contribuindo para outras alternativas para além do ciclo punitivo de classificação e quantificação obtidos por, unicamente, exames de verificação que são confundidos com a real avaliação (LUCKESI, 2000).

A avaliação deve ser feita no processo, já que a aprendizagem é contínua e seu acompanhamento serve para conhecimento das potencialidades e limitações dos estudantes, além de ajudar o docente a trilhar o caminho do seu planejamento. Nesse processo, ainda, percebe-se a preocupação na frequência escolar, seja pela realização de atividades ou participação efetiva, insinuando que para efetivação da avaliação há uma necessidade da presença no processo da aprendizagem (DOMINGUES, 2020).

Portanto, a adesão ao ensino remoto emergencial é uma necessidade imposta para combater e minimizar a proliferação do vírus da Covid-19, sendo que tal modelo de educação foi adotado para garantir a continuação do processo educativo (BRITO; COSTA, 2020). Com isso, percebe-se que há déficits nas adaptações, mas também são evidentes outras possibilidades educativas e um constante aprimoramento e renovação, conforme afirma a Escola M3 sobre o momento atual de incertezas. Ou seja, as ações desenvolvidas são constantemente adaptadas e reavaliadas (BRITO; GARCIA; MORAES; MATEUS, 2020), e evidenciar suas tentativas é

Revista Extensão \& Cidadania, v. 9, n. 15, p. 93-109, jan./jun. 2021.

ISSN 2319-0566 DOI: 10.22481/recuesb.v9i15.8649 
essencial para buscar um método estrutural mais justo que ultrapasse esse momento e que possa ter reverberações nos sistemas avaliativos após o retorno para o ensino presencial.

\section{Considerações finais}

A educação básica é um direito, firmado pela Constituição Nacional, sendo assim, é um direito de todos estudantes o acesso ao sistema de ensino, mesmo que o atual contexto seja de incertezas e mudanças sociais e políticas. Com a Pandemia de Covid-19 decretada em 2020, que apresenta o distanciamento social como mecanismo de prevenção e contenção da disseminação do vírus, a estrutura física tradicional de ocorrência do processo do ensino básico, a escola, teve que ser fechada em prol da tentativa de manutenção da saúde pública. Entretanto, esse fechamento está associado à estrutura de concreto escolar, não ao processo de educação.

Para assegurar o processo de ensino-aprendizagem na educação nas escolas, houve a necessidade de adaptação do ensino para a modalidade de Ensino Remoto Emergencial, no qual diferentes metodologias que contribuem para esse processo foram adotadas, e interferiram diretamente no sistema avaliativo escolar. Este sistema, frequentemente é associado ao formato de exames impositivos e autoritários tendo que ser remodelado para objetivos que visem acompanhar e compreender a aprendizagem durante a implementação desse modelo de ensino. Sendo assim, ficam visíveis as tentativas de adesão dos sistemas avaliativos com diferentes ferramentas e sistemas que destacam questões já ocorrentes durante o ensino presencial, como o déficit na formação docente continuada e o contraste entre os sistemas públicos e privados.

Nesse sentido, algumas mudanças foram implementadas e podem efetivar melhorias no ensino durante o retorno para os modelos presenciais, como a diversificação dos sistemas avaliativos, modelos processuais não impositivos e a educação como um processo gradual, que necessita de uma frequência, que deve ser avaliada processualmente. Assim a Educação Remota Emergencial abre espaço para evidenciar a importância sobre a associação de tecnologias e meios digitais aos métodos pedagógicos e sistemas avaliativos, indicando caminhos para que essa associação ocorra em situações corriqueiras, relacionadas a vida dos estudantes, e a avaliação seja significativa.

Portanto, o momento é de possibilidades e incertezas, mas ao mesmo tempo as realizações e melhorias obtidas podem trazer boas práticas e influências no retorno presencial. A constante readaptação se faz presente entre estudantes, docentes, equipe pedagógica e toda

Revista Extensão \& Cidadania, v. 9, n. 15, p. 93-109, jan./jun. 2021.

ISSN 2319-0566 DOI: 10.22481/recuesb.v9i15.8649 
comunidade escolar. A apresentação e exposição de diferentes sistemas avaliativos se faz necessária, para refletir sobre modelos pedagógicos e avaliações mais efetivas e significativas, e que concepções de verificação tradicional sejam reduzidas a favor de uma educação por e para os estudantes, objetivando seu desenvolvimento integral, e não apenas uma classificação. Por fim, a exposição dos resultados encontrados abre espaço para pensar o processo de qualificá-las e melhorá-las, além de evidenciar as tentativas para tornar o sistema avaliativo mais justo e a aprendizagem no período da Pandemia um pouco mais equilibrada.

\section{Referências}

BITTENCOURT, P. A. S.; ALBINO, J. P. O uso das tecnologias digitais na educação do século XXI. Revista Ibero-Americana de Estudos em Educação, Araraquara, p. 205-214, 2017.

BRASIL. Constituição da República Federativa do Brasil. Diário Oficial. 1988. Disponível em:

http://www.planalto.gov.br/ccivil_03/constituicao/constituicao.htm\#: :text=Art.\%206\%C2\% BA $\% 20 \mathrm{~S} \% \mathrm{C} 3 \% \mathrm{~A} 3 \mathrm{o} \% 20$ direitos $\% 20$ sociais,desamparados $\% 2 \mathrm{C} \% 20$ na $\% 20$ forma $\% 20 \mathrm{desta} \%$ 20Constitui\%C3\%A7\%C3\%A3o. Acesso em: 2 maio 2021.

BRASIL. Ministério da Educação. Secretaria da Educação Básica. Base Nacional Comum Curricular. Brasília, DF, 2018. Disponível em: http://basenacionalcomum.mec.gov.br/ . Acesso em: 29 abr. 2021.

BRASIL. Ministério da Saúde. Como se proteger? 8 de abril de 2021. Disponível em: https://www.gov.br/saude/pt-br/coronavirus/como-se-proteger. Acesso em: 19 abr. 2021.

BRASIL. Portaria no $\mathbf{3 4 3}$, de 17 de março de 2020. Dispõe sobre a substituição das aulas presenciais por aulas em meios digitais enquanto durar a situação de pandemia do Novo CORONAVÍRUS - COVID-19. D.O.U 18/03/2020. Disponível em: https://www.in.gov.br/en/web/dou/-/portaria-n-343-de-17-de-marco-de-2020-2485643767. Acesso em: 19 abr. 2021.

BRITO, G. S.; GARCIA, M.; MORAIS, F A. F.; MATEUS, M. C. A reconfiguração de aulas no período pandêmico percepções de professores das escolas públicas de ensino do estado do Paraná - Brasil. Interações, v. 16, p. 186-206, 2020.

BRITO, G. S.; COSTA, M. L. F. Apresentação - Cultura digital e educação: desafios e possibilidades. Educar em Revista, v. 36, p. 1-7, 2020.

CARVALHO, E. M. S.; ARAÚJO, G. C. Ensino remoto, saberes e formação docente: uma reflexão necessária. Revista Cocar, v. 14, n. 30, 2020.

Revista Extensão \& Cidadania, v. 9, n. 15, p. 93-109, jan./jun. 2021.

ISSN 2319-0566 DOI: 10.22481/recuesb.v9i15.8649 
CHUIEIRE, M. S. F. Concepções sobre a avaliação escolar. Estudos em avaliação educacional, v. 19, n. 39, p. 49-64, 2008.

CRESWELL, J. W. Projeto de pesquisa: métodos qualitativo, quantitativo e misto. Trad. Magda Lopes. 3. ed. Porto Alegre: Artmed, 2010.

DE OLIVEIRA, H. V. DE SOUZA, F. S. Do conteúdo programático ao sistema de avaliação: reflexões educacionais em tempos de pandemia (COVID-19). Boletim de Conjuntura (BOCA), v. 2, n. 5, p. 15-24, 2020.

DOMINGUES, S. C. Conteúdo, Metodologia do ensino e avaliação da aprendizagem da educação física I. 2020. (Material didático Universidade Federal do Paraná, Material didático para Universidade Aberta do Brasil, CAPES).

DOMINGUES, S. C.; JAIME, M. C. R. (org.). Relatório técnico científico do Programa Licenciar em Tempos de Isolamento Social, Universidade Federal do Paraná, 2020, UFPR, Curitiba, 2020. Mimeografado.

FREIRE, P. Pedagogia da autonomia: saberes necessários à prática educativa. 63. ed. Rio de Janeiro: Paz e Terra, 2020.

GONÇALVES, C. J.; ANTONIO, D. A. As múltiplas linguagens no cotidiano das crianças. Zero-a-Seis, v. 9, n. 16, p. 85-108, 2007.

HODGES, C.; MOORE, S.; TRUST, T.; BOND, A. The Difference Between Emergency Remote Teaching and Online Learning. Educause Review, 2020. Disponível em: https://er.educause.edu/articles/2020/3/the-difference-between-emergency-remote-teachingand-online-learning. Acesso em: 21 abr. 2021.

KENSKI, V. M. Educação e tecnologias: o novo ritmo da informação. 8. ed. Campinas: Papirus, 2012.

KUNZ, E. Educação Física: ensino e mudança. Unijuí; Ed. da Unijuí, 1991.

LUCKESI, C. C. Avaliação da aprendizagem na escola: reelaborando conceitos e recriando a prática. 2005. p. 115-115. Disponível em:

https://pesquisa.bvsalud.org/portal/resource/pt/sus-8954 . Acesso em: 22 abr. 2021.

LUCKESI, C. C. O que é mesmo o ato de avaliar a aprendizagem. Revista Pátio, v. 12, p. 6$11,2000$.

LUCKESI, C. C. Verificação ou avaliação: o que pratica a escola. Série Ideias, n. 8, p. 71-80, 1998.

NASCIMENTO, E. N. GIMENIZ-PASCHOAL, S. R. Estratégias de avaliação do aluno: uma análise de programas de ensino de cursos de fonoaudiologia. Distúrbios da Comunicação, v. 20, n. 3, 2008.

Organização Mundial da Saúde (OMS), Organização Pan-americana de saúde (OPAS). Folha informativa - COVID-19 (doença causada pelo novo Coronavírus). 11 de Março de 2020

Revista Extensão \& Cidadania, v. 9, n. 15, p. 93-109, jan./jun. 2021.

ISSN 2319-0566 DOI: 10.22481/recuesb.v9i15.8649 
Disponível em:

https://www.paho.org/bra/index.php?option=com_content\&view=article\&id=6120:omsafirma-que-covid-19-e-agora-caracterizada-como-pandemia\&Itemid=812. Acesso em: 19 abr. 2021.

PALFREY, J. GASSER, U. Nascidos na era digital: entendendo a primeira geração de nativos digitais. Trad. Magda França Lopes. Porto Alegre: Artmed, 2011.

PARANÁ. Conselho Estadual de Educação. Secretaria de Educação e do Esporte

Deliberação n. 0 01/2020-CEE/PR, Curitiba, PR, 2020. Disponível em:

http://www.cee.pr.gov.br/sites/cee/arquivos_restritos/files/documento/2021 -

03/deliberacao_01_20_alt_02_e_03-20_0.pdf Acesso em: 10 maio 2021.

RONDINI, C. A.; PEDRO, K. M.; DUARTE, C. S. Pandemia do Covid-19 e o ensino remoto emergencial: Mudanças na práxis docente. Interfaces Científicas-Educação, v. 10, n. 1, p. 41-57, 2020.

SARAIVA, K. T. C.; LOCKMANN, K. A educação em tempos de COVID-19: ensino remoto e exaustão docente. Práxis Educativa, Ponta Grossa, v. 15, e2016289, p. 1-24, 2020.

SCHON, D. Os educadores e sua formação. Portugal. Dom Quixote, 1997.

UNESCO. Crise da Covid-19: UNESCO pede apoio ao compartilhamento de aprendizagem e conhecimento por meio de Recursos Educacionais Abertos. 28 de Abril de 2020. Disponível em: https://pt.unesco.org/news/crise-da-covid-19-unesco-pede-apoio-ao-compartilhamentoaprendizagem-e-conhecimento-meio. Acesso em: 28 abr. 2021.

Recebido: 07.05.2021

Aceito: 19.06 .2021

Revista Extensão \& Cidadania, v. 9, n. 15, p. 93-109, jan./jun. 2021.

ISSN 2319-0566 DOI: 10.22481/recuesb.v9i15.8649 